\title{
Assessment of Indigenous Knowledge of Farmers on Soil Fertility Management: In Case of Bule Hora Woreda, West Guji Zone, Bule Kegna Kebele
}

\author{
KOAT MACHAR ${ }^{1} \quad$ Abdissa Debela $^{1^{*}}$ \\ ${ }^{1 *}$ Department of Natural Resource Management, College of Agricultural Sciences (CAS), Bule Hora University \\ (BHU), P.O. Box: 144, Oromia, Ethiopia \\ ${ }^{1}$ Graduate student from Department of Natural Resource Management at Bule Hora University, Oromia, Ethiopia
}

\begin{abstract}
The study was conducted in Bule Kenga kebele to assess the indigenous knowledge of community on soil fertility management. The main objective of this study was to assess the Indigenous knowledge of farmers on soil fertility management in the study area. The data was collected through household survey, interviews, questionnaire and observation. To do so, one samples kebeles were used. Accordingly, the majority of the respondents revealed that indigenous soil fertility management together with natural resource management was very significant, at community level. Local farmers know their own strength, forces knowledge, and technique to conserve soil even hilly lands. The major indigenous knowledge of soil fertility management in the study area was crop rotation, Organic fertilizer, Agroforestry, intercropping, and green manure. As a result the, majority of respondents (57\%) reported that they had knowledge on the soil fertility management whereas $43 \%$ had no knowledge on soil fertility management. As the result shows, out of the total respondents, $60 \%, 26 \%, 9 \%$, and $6 \%$ of the respondents said role of indigenous knowledge of soil fertility improvement were good, better, best and bad, respectively. The traditional land management practices improved cropland productivity through addition of organic matter to the soil, adding nitrogen, maintaining organic matter and plant nutrients, and improving soil structures increasing water infiltration and reducing run off. Lastly local knowledge ought not to be ignored because it has own attribution to reduce the soil fertility problems which in line with the current study area
\end{abstract}

DOI: $10.7176 /$ JEES/11-8-03

Publication date:August $31^{\text {st }} 2021$

\section{INTRODUCTION}

Agriculture remains the backbone of the Ethiopia economy and so deserves critical attention. Soil fertility was a fundamental in determining the productivity of all farming system. People of world depend up on soil to produce food crop. Where the soil was fertile and where the society has the means to improve fertility good crop can be grown. As mentioned in Taffa (2002) economic sustainability develops from good soil used intelligently and protect the soil erosion are unnecessary wastage of rain fall by excessive run off. In Ethiopia soil fertility problem was the results of human failures to understood and manage the soil .In the most part of agrarian country the soil fertility problem was the accumulation effects of deforestation, over grazing, burning of forests, clearing of ground cover (Taffa, 2002). According to FAO (2001), the decline of soil productivity was attributed to high population preserve which intern leads to deforestation, over grazing and misses used of land. Problem of soil fertility was perceived as the greatest threat to sustainability of agricultural production in the developing countries. According to Taffa (2002), the role of indigenous knowledge that contributes soil fertility management through practiced of physical ,biological and mechanical way have central and cuties role at grass root level .Indigenous knowledge plays a crucial role in conserving of natural resource ,forest, soil etc. through applying different kinds of soil fertility management practice.

In this study, local or indigenous knowledge was defined as skills and practices of the people living in a certain area generated by their own and their ancestors' experience as well as those originating from elsewhere which has been internalized by the local people. Soil fertility management refers to any strategy employed by farmers to maintain and possibly increase soil fertility for sustaining crop productivity through optimizing all possible sources of plant nutrients needed for crop growth and appropriate to each crop system and specific ecological and socioeconomic situation. The Indigenous knowledge plays crucial role in improved of soil fertility specifically at the Guji zone, south of Ethiopia particular in Bule Hora Woreda. The soil fertility problem in this area might be due to depletion of natural resource, mis-management of natural resource, poor farming system and failure of practiced, which result in high erosion, depletion of nutrient from plant root, deterioration of physical soil surface and less productive soil. The focus of this study, therefore, was on the indigenous knowledge perspective of soil fertility management. 


\subsection{Objectives of the study}

1.3.1 General objectives

The General objective of the study was to assess the Indigenous knowledge of farmers on soil fertility management

\subsubsection{Specific objectives}

$\checkmark$ To assess farmers perception for soil fertility improvement in the study area

$\checkmark$ To identify indigenous soil fertility management practiced that can promote to sustainable agriculture production.

\section{MATERIAL AND METHOD}

\subsection{Description of the study area}

\subsection{Location and Climatic condition}

The Bule hora district was one of the districts in West Guji zone, Oromia region. It is located in south from Yabello and $467 \mathrm{~km}$ in from Addis Ababa, and in the west by southern nation and nationalities, people and north by the Ganale Dorya Rivers which separate it from Bale zone and on the east by the Somalia region. Total areas coverage was about 6021 square kilometer with an altitude range from 500-2800 m.a.s.1 level and it have the 32 kebele. Annual rainfall of the district range between $750-1500 \mathrm{~mm}$ per year and it has three agro-ecology zone, were the bada dare (Wayina dega), Bada "dega" and Gamojii (kola). Most of the kebele were found in the high land climatic zone and average temperature range from 15 to 30 and agriculture was the main sources of income for the farming communities (West Guji zone agricultural office, 2018).

\subsubsection{Demographic Information and Land use system}

Population of Bule Hora Woreda belongs at most to five ethnic groups: namely Guji Oromo, Burji, Amara, Gurage and koira. According to the current Housing and census data appointed the total population of Bule Hora Woreda was 266,150 of which 134,603 and 131,547 was male and female respectively (Bule hora agricultural office, 2018). The rural settlement pattern was more of scattered and even in some places of the 'kola 'area no constant settlement pattern. However, a few farmers were seen settled at areas where social service like market and the like are situated and this created rural village. According to the Agricultural Office of the Bule Hora Woreda, (2018), some of the dominant crops that were produced in the Woreda include maize, enset, teff, barley, wheat, soybean and beans. These crops were used for home consumption. The Woreda also produces some cash crops such as coffee, chat, inset and different varieties of fruits. Livestock was the main economic based of the community of the areas, which of the most economic activities were livestock production and agricultural production (Bule hora Woreda agricultural and rural development, 20018).

\subsubsection{Sampling size and technique}

Bule Kenga Kebele was selected from Bule Hora Woreda purposively based on their involvement in different crop production activities, presence of soil fertility problem such as deforestation, farming system and soil erosion. Households were purposively selected based on their involvement in crop production activities. This was because of the fact that it could have been meaningless to interview farmers non-participating on crop production activities farmers about soil fertility management system in the area. The total household of the kebele is 600, (Bule hora Woreda agricultural office 2018). Because of time limitation, lack of finance and large number of households, 35 households of the respondents was selected by used purposively sampling techniques from 600 household of the Bule Kenga kebele.

\subsection{Methods of data collection}

Survey was conducted to assessed Indigenous Knowledge of Farmers on Soil Fertility Management status in Bule Haro Woreda, West Guji Zone. To achieve the objective mentioned the above, data were collected through primary and secondary source. Primary data was collected from respondents by interview, questionare, focus group discussion and personal and direct observation of the study area. Secondary data was collected from book, research reports, internet and both publishes and unpublished materials and annual report of the kebele office.

\section{RESULT AND DISCUSSION}

The results from the household survey, key informant interviews with the representatives of the community and focus group discussion with the farmers of the Bule kenga are discussed under this chapter.

\subsection{Personal Data (household Characteristics)}

\subsubsection{Household Size}

Family was one of the social institutions that has play vital role in the process of socialization and performing collective work. As shown in table 1, the family size less than 3 accounts for $25.7 \%$. The majority of the respondents $(28.6 \%)$ were in the categories of 4-6 family members. The respondent with family size between 7 and 9 accounts for $25.7 \%$, and the remaining $20 \%$ had family size above 10 . The nature and size of family affects the soil fertility. As clearly known soil and water conservation structure and soil fertility management 
need more labor intensive so, households with larger family size make easily SWC structures and soil fertility management implement on their farm land. According to the respondents, large family size was very important for soil conservation measures because having a small number of children requires additional labor from out of family to construct and maintain soil conservation structures and managing of soil fertility such as applied manure, compost. The result consistent with the assertion that the size of households was the major constraints to the adoption of the soil fertility management practices (Franzel, 1999).

Table 1: Family size of respondents

\begin{tabular}{lll}
\hline Family size & Number of Farmers & Percentage \\
\hline \hline$<\mathbf{3}$ & 9 & $25.7 \%$ \\
$\mathbf{4 - 6}$ & 10 & $28.5 \%$ \\
$\mathbf{7 - 9}$ & 9 & $25.7 \%$ \\
$>\mathbf{1 0}$ & 7 & $20 \%$ \\
Total & 35 & 100 \\
\hline \hline
\end{tabular}

(Source: own field survey, 2018)

\subsubsection{Age-Sex characteristics}

Age was one of the major factors that could play a significant role in the study area for the soil fertility management activities. As the table 2 shows, from the field survey, the majority of $51.84 \%$ of the respondent lies in the age between $35-60,22.8 \%$ of the respondents lies in the age between $25-35,20 \%$ of the respondents lies in the age between $15-25$, and the $5.7 \%$ of the respondents lies in the age between $7-12$. According to the respondent, most of the household heads (37\%) were in the age category between 25-35 years. Farmers in this age group (25-35) are to have a good understanding of the problem of soil fertility. As explored through interview, farmers of these age groups to have a good understanding on the problem of soil-water conservation, soil fertility management and usually interested in implementing soil fertility management practices than the other age group. Knowledge and skills developed during long periods of farming is of vital importance to the practice of sustainable agriculture

Table 2. Distribution of Farmers by age

\begin{tabular}{lcc}
\hline \hline Age & Number of Farmers & Percentage \\
\hline \hline $\mathbf{7 - 1 2}$ & 2 & $5.7 \%$ \\
$\mathbf{1 5 - 2 5}$ & 7 & $20 \%$ \\
$\mathbf{2 5 - 3 5}$ & 8 & $22.8 \%$ \\
$\mathbf{3 5 - 6 0}$ & 18 & $51.84 \%$ \\
$>\mathbf{6 0}$ & - & - \\
Total & 35 & 100 \\
\hline \hline
\end{tabular}

\subsubsection{Education Status}

The study has identified four educational levels in the study district: illiterate, can read and write, elementary schooling and secondary schooling. From the survey result, about $20 \%$ of the household heads had no formal education, $11.5 \%$ of the respondent can read and write, $60 \%$ have primary schooling and $8.5 \%$ secondary schooling as shown in the table3. Educational level of the community was one of the determining factors for management of the soil fertility.

Table3.Educational back ground of respondents

\begin{tabular}{lcc}
\hline Educational Back ground & Number of Farmers & Percentage \\
\hline \hline Illiterate & 7 & $20 \%$ \\
Only read and write & 4 & $11.5 \%$ \\
Secondary school & 3 & $8.5 \%$ \\
Primary school & 21 & $60 \%$ \\
Total & 35 & $100 \%$ \\
\hline \hline
\end{tabular}

Source: from my survey 2018

As the questionnaire survey indicates, the majority of $42 \%$ of the respondents were protestant followed by orthodox (22\%), Muslims (15\%), catholic (15\%) and other religion (6\%) as shown in figure1. As response from group-discussion, indicate that having this different religion in one kebele have no any influence on the practice of soil fertility management 


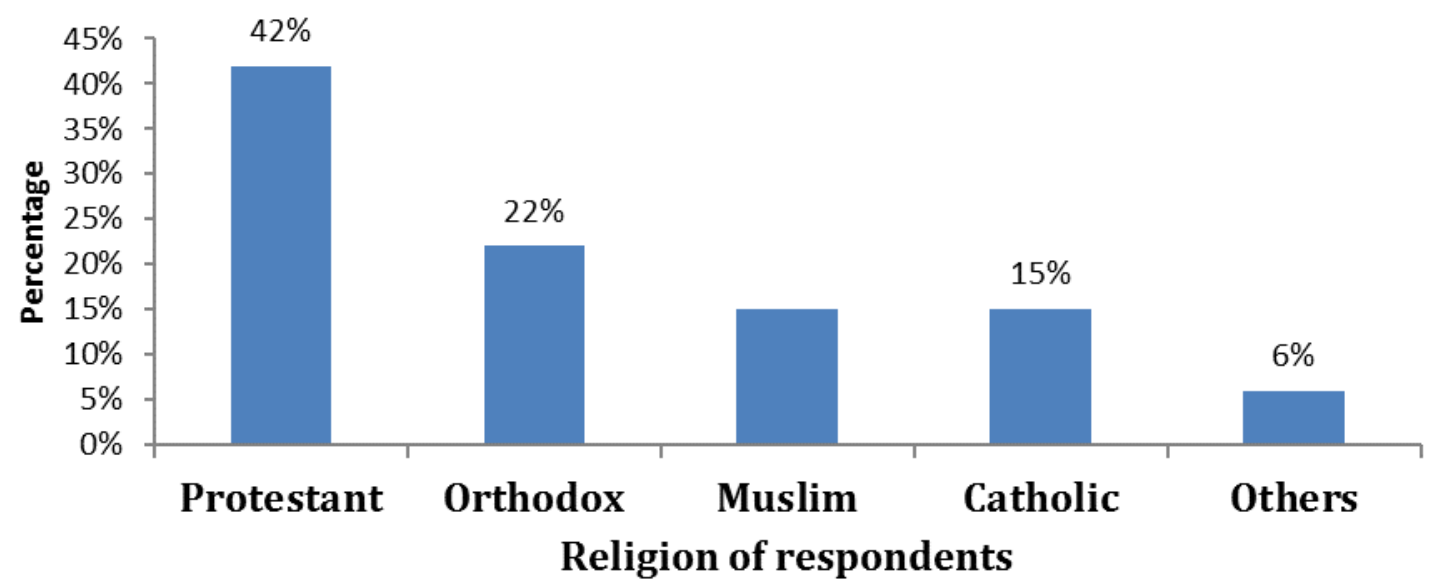

Figure1. Religion of the respondents

\subsection{Farmers' perception on soil fertility management}

From the total 35 respondents as it shown in the table4, $20 \%$ of the respondent had comment on the deforestation, $68.57 \%$ of the respondent comment on the soil erosion, $5.7 \%$ of the respondents perceived on soil poor farming practices and $5.7 \%$ of respondent comment on expansion of the absence of crop rotation. Most of respondents characterized fertile soil in dark rich in biodiversity and infertile soils are red, poor in biodiversity, and less productive. Farmers stated as they always harvest good yield from fertile soil. It is the wearing always, detachment and removal of soil from one place to another and it is deposition at another through the forcing of striking, moving water and blowing wind (Hanhum, 1986)

Table4. Farmer's perception on soil fertility depletion

\begin{tabular}{lrr}
\hline \hline Status & No of respondents & Percentage (\%) \\
\hline \hline Soil erosion & 24 & $68.57 \%$ \\
crop rotation & 2 & $5.7 \%$ \\
Deforestation & 7 & $20 \%$ \\
Poor farming practices & 2 & $5.7 \%$ \\
Total & 35 & $100 \%$ \\
\hline \hline
\end{tabular}

Source: from my survey 2018.

As shown in the figure2, 54\% of the respondents replied that the current agricultural production is increasing when compared to the previous agricultural production. From the basis of reflection it is concluded that due to different indigenous knowledge of soil fertility practices like green manure, agro forestry, and composting and animal manure enhance the productivity of the soil. Consequently the combined integrated biophysical conservation method applying in the area intensively are collectively promotes sustainable agricultural production and this finding agreement with the Scronth and Sinclair (2002), suggested that the use of tree in agroforestry can improve the nutrient balance of the site, both by reducing unproductive nutrient loss from erosion and by increasing nutrient input, through nitrogen fixation that can improve the soil fertility and water, increasing the biological activities in the soil by providing the biomass and suitable microclimate.

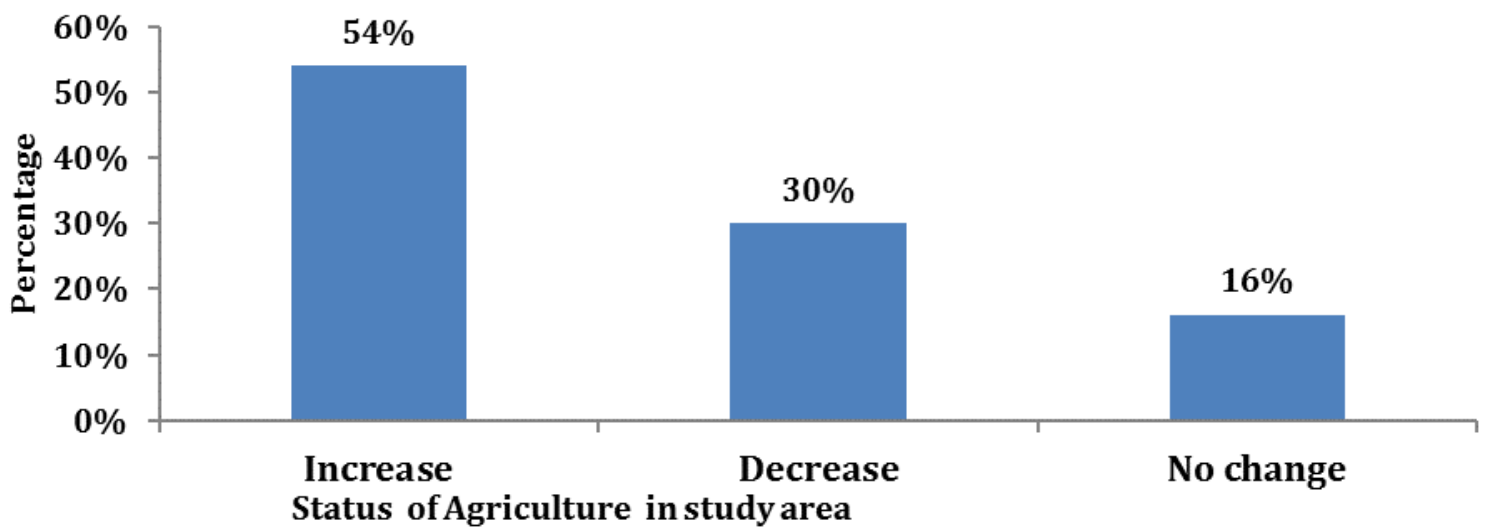

Figure2. Shown an indigenous knowledge of farmers on status of agriculture productivity 


\subsection{1 .Indigenous knowledge of farmers on soil fertility depletion}

This deal with the attitudes of farmer towards soil conservation and also deal with the knowledge of local people have on soil fertility depletion. As show in the table 5 below $74.3 \%$ of the respondents had knowledge on the soil fertility depletion and $25.7 \%$ of the respondents had no knowledge on soil fertility depletion ,the role of indigenous knowledge for soil fertility depletion in the study area as the same the other researcher said before and this finding agreement with the (Toflg, 2001). Because the indigenous of the farmer were very important for the soil fertility management practices such as manure, crop rotation, intercropping and leaf litter to some extents. Table5. Knowledge on soil fertility depletion

\begin{tabular}{lll}
\hline \hline Have knowledge on soil fertility depletion & Number of respondent & Percentage (\%) \\
\hline \hline YES & 26 & $74.3 \%$ \\
NO & 9 & $25.7 \%$ \\
Total & 35 & 100 \\
\hline \hline
\end{tabular}

Source: from my survey 2018.

4.2.2. Attitude of farmers towards soil fertility improvement

Most farmers have developed good attitude towards soil fertility improvement and some farmer have medium interest towards soil fertility improvement practices. The table6 shown that, most of the respondents were $54.28 \%$ low perceptions towards using soil fertility management practices, this were consistent with the previous study (Muhammed, 2007) found that labor problem, economic problem and lack of awareness were major factors that hinder farmers from performing soil fertility management practices .

Table6. Farmer perceptions towards soil fertility improvement

\begin{tabular}{lll}
\hline \hline Variable & Respondents & Percent \\
\hline \hline Low & 19 & $54.28 \%$ \\
Medium & 9 & $25.71 \%$ \\
High & 7 & $20 \%$ \\
Total & 35 & $100 \%$ \\
\hline \hline
\end{tabular}

Source: from my survey 2018

\subsection{Farmers Indigenous Knowledge on soil fertility management practices}

Regarding soil fertility management as shown in table, majority of respondents $(57 \%)$ reported that they had knowledge on the soil fertility management whereas, the remaining $43 \%$ had no knowledge on soil fertility management. Different finding showed that the indigenous knowledge on soil fertility improvement plays a great role. According to Young (1989), the use of trees, different agro forestry practice, use of terrace, counter bund, mulching, green manure are highly significant on soil fertility improvement. Thus, the finding of this study also agreed that the role of indigenous knowledge on soil fertility improvement contribute a major role in improving physical soil structures, maintain and increase soil fertility, conserving different biodiversity and enhancing vegetation and forest maintenance.

Table7. Knowledge on the soil fertility management

\begin{tabular}{lll}
\hline \hline Have knowledge on the soil fertility management & Respondent & Percentage (\%) \\
\hline \hline YES & 22 & $62.8 \%$ \\
NO & 13 & $37.14 \%$ \\
Total & 35 & $100 \%$ \\
\hline \hline
\end{tabular}

Source: from my survey 2018.

As shown in the table7, out of the total respondents, $60 \%, 25.71 \%, 8.57 \%$, and $5.71 \%$ of the respondents said role of indigenous knowledge of soil fertility improvement were good, better, best and bad, respectively Table8. Role of indigenous knowledge for soil fertility management

\begin{tabular}{lcc}
\hline \hline Status & Farmers & Percentage (\%) \\
\hline \hline Good & 21 & $60 \%$ \\
Better & 9 & $25.71 \%$ \\
Best & 3 & $8.57 \%$ \\
Bad & 2 & $5.71 \%$ \\
Total & 35 & $100 \%$ \\
\hline \hline
\end{tabular}

Source: from my survey 2018

The majority $22.85 \%$ of the respondents were replied that it is good for soil fertility management practices such as, crop rotation and $8.57 \%$ used the crop residues and other soil fertility management practices were 
$17.14 \%, 8.57 \%$ and $5.71 \%$ for agroforestry, green manure and composting, respectively while mulching, tillage and intercropping were $8.57 \%, 5.71 \%, 2.85 \%$ and $8.57 \%$, respectively. There were a number of soil fertility management practices that are important for the improving the fertility of the soils (Morgan, 1996). These include organic fertilizer, inorganic fertilizer, terracing, intercropping and others. The majority of the respondents use other soil fertility management practices include cover crop, mixed cropping, and others, while inorganic fertilizer had not been well available due to lack of awareness and lack of capital to apply practices. Indigenous soil fertility management practices were very important to improve soil fertility and increasing of the agricultural productivity. In the study area, some farmers used cow dung to add fertility to the soil where farmers feel that the soil exhausted they add cow dung to its. This was more frequently used in the areas when the mixed farming was more dominant. Ethiopian farmers use household refuse and leaf litter to improve soil fertility that was agreement with the (Murdoch book, 2004).

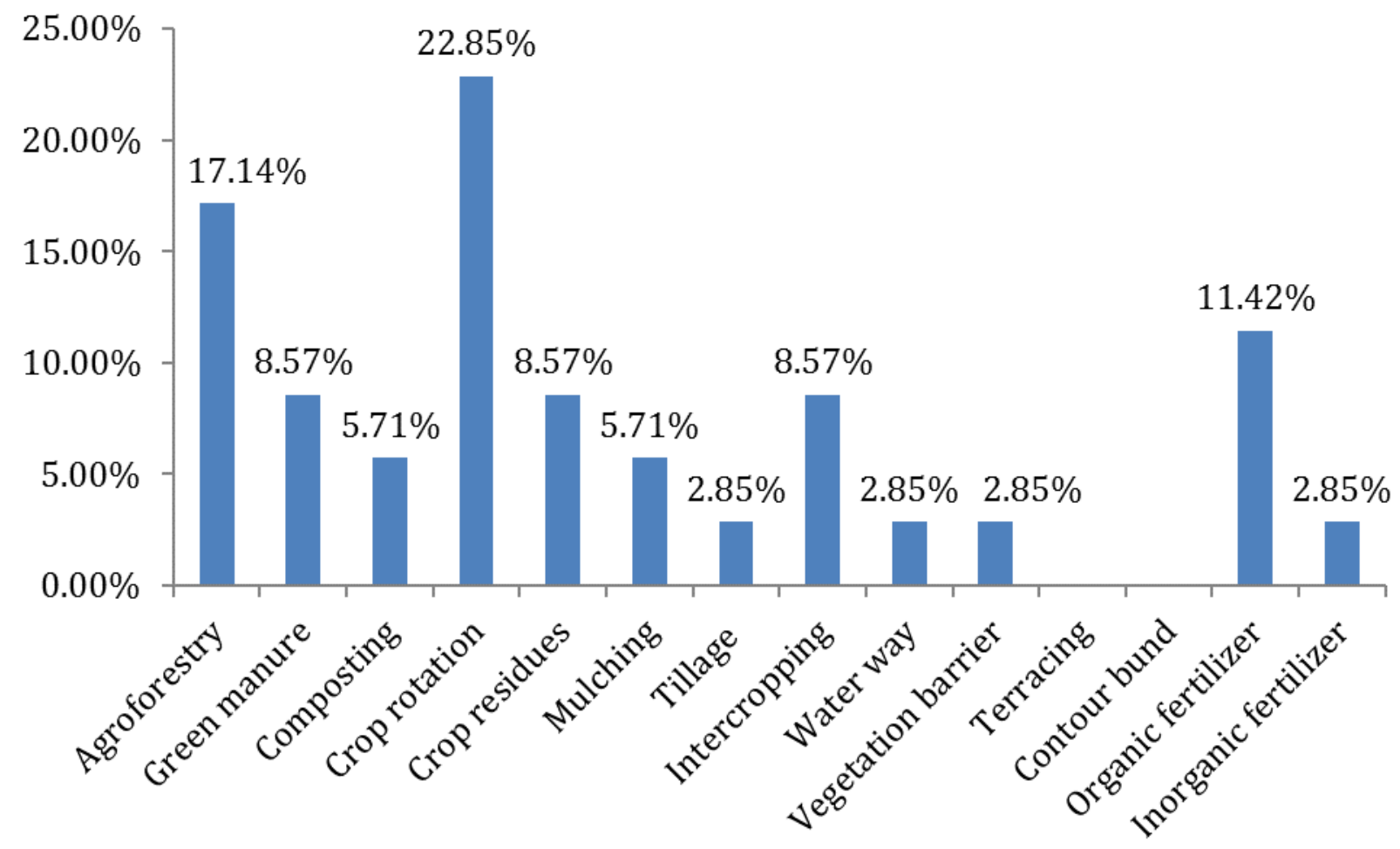

Figure3. Shows methods of soil fertility management in the study area

\section{Conclusion and Recommendation}

Based on the finding of the study, soil fertility depletion recognized in the Bule Kenga Kebele was mostly resulted from human activities that could accelerate soil erosion in the study area. Topography, deforestation, improve land use system, over grazing, in appropriate tillage are the main cause of soil erosion. The clearing of forest and disturbance of its ecosystem exposed the fertile soil for erosion and this in turn decrease the fertility of the soil. Farmers have developed conservation and land management system on own knowledge which is the basis for sustainable agriculture and natural resource management. Apparently, indigenous soil fertility practices are many various biophysical, agro economic and different soil fertility management practices are considered as building block in designing the new ones. The study area revealed different indigenous soil fertility management practices which are used for sustainable SFM practices while conserving soil, land, and natural resource by indigenous community dwelling in the area. According to in the study area, respondent indicated that traditional indigenous soil fertility management is every aspect as contributes to sustainable agricultural productivity.

\section{Recommendation}

To meet the comprehensive, integrate, holistic and sustainable agricultural production, the following points should not be undermined.

$\checkmark \quad$ The relatively less practiced physical and biological soil conservation measures should be applied properly and wisely.

$\checkmark$ Community of indigenous knowledge of SFM should get adequate, tangible, technical and material support from government and non-governmental organization to improve or run physical and biological soil fertility conservation measures. 
$\checkmark$ Thus, indigenous soil fertility management practice in all direction should be encouraged without neglecting the combined, integrated, holistic and sustainable agriculture experts, managers in study area.

$\checkmark$ Generally the food we eat and most of minerals we use for different purpose are coming from soil directly or indirectly. So, maintenance of soil fertility and conservation of the precious soil resource is very important.

\section{REFERENCES}

FAO (2001) Soil Fertility Management in support of Food Security in sub-Saharan Africa, Food and Agriculture. Hand son, N.W.(1981).Soil Conservation B.T Bats ford LTD London.

Hunch,(1998) Degradation and Soil Conservation in Ethiopia high land a paper presented at the first International Work shop on Africa Maintain and High lands Addis Abe be October 13-27

Helmut honker and Anson R.Betrand, 2009 .Soil Conservation Measure and Control Page 44-45.India-Perdne University

Hans Humin, 1986 Guide lines for Development agent in Soil Conservation in Ethiopia.

Krubel Melese (2002).Impact Assessment of Biological Conservation Measure on the Soil and Socio-economic in Gergel area Tigray.

Morgan, R.P.C,(1993) Soil Erosion and Soil Conservation.

Murdoch Book (2004) Vege tation gardening, growing and Harvesting Vegetable PP.

Schwab and Glenn (1993). Soil and Water Conservations Engineering (4 ${ }^{\text {th }}$ Ed)New York, John and Son.

Taffa Tulu (2002).Soil and Water Conservation for Sustainable Development and .Addis Ababa. Mega publishing enterprise.

Tofinga M (2001).An over view of traditional Farming System in the pacific Islands proceeding of IRETA work shop, Alafual campus, Journal of pacific Agriculture.

Tom ado Tanah,(2oo2).Teaching Material for principle and practices of GDP Production.

Young, A.(1989).Agroforestry for Soil Conservation CAB International UKs. 